\title{
The feasibility and efficacy of gonadotropin-releasing hormone agonists for prevention of chemotherapy induced ovarian failure in patient with gynecological malignancies
}

\author{
Chan-Yong Park, Sun-Young Jung, Kwang-Beom Lee, Sun-Hye Yang \\ Department of Obstetrics and Gynecology, Gil Hospital, Gachon University of Medicine and Science, Incheon, Korea
}

\section{Objective}

To assess the effects of a gonadotropin-releasing hormone agonist (GnRH-a) depot (Leuprolide acetate) in women with gynecologic cancer receiving chemotherapy while taking a continuous add-back on the prevention of premature ovarian failure.

\section{Methods}

Fourteen premenopausal patients with gynecological malignancies who had undergone conservation of ovaries surgery received a GnRH-a depot plus add-back until chemotherapy was completed. Four weeks thereafter, a hormonal profile (follicle stimulating hormone) was measured.

Results

The mean follicle stimulating hormone level was $15.8 \mathrm{IU} / \mathrm{L}$. All patients exhibited a restoration of ovarian failure during follow-up. One patient became pregnant during the follow-up period.

\section{Conclusion}

In the short term, GnRH-a appears to protect ovarian function and ability to achieve pregnancy following chemotherapy. The result of our study needs further elucidation in a large randomized controlled trial.

Keywords: Adjuvant chemotherapy; Fertility preservation; Gonadotropin releasing hormone agonist; Ovarian neoplasms; Uterine cervical neoplasms

\section{Introduction}

The reported incidence of cancers among women aged 15 to 34 years is reported to be 106 per 100,000 women in Republic of Korea. They are 5.4 per 100,000 women for cervical cancer, 3.1 per 100,000 women for ovarian cancer [1]. When detected in early stages, most gynecologic cancers have a good cure rate. Gynecologic oncologists are concerned not only with provision of a disease-free state but also with preservation of an optimum quality of life after cancer treatment as development in treatment regimens and supportive care strategies. Ovarian preservation has become a major issue to gynecologic oncology in premenopausal patients, due to both the increasing age at childbearing and the increasing incidence of gynecologic cancer in young patients. These days, possibility of preservation of fertility primarily depends on the extent and type of cancer in young patients with gynecologic cancer. Current options for preservation of fertility in gynecological cancer patients before the initiation of cancer-directed therapy are ovarian suppression and cryopreservation of embryo or un-

Received: 2014.3.28. Revised: 2014.5.21. Accepted: 2014.6.13. Corresponding author: Kwang-Beom Lee

Department of Obstetrics and Gynecology, Gil Hospital, 21

Namdong-daero 774beon-gil, Namdong-gu, Incheon 405-760, Korea

Tel: +82-32-460-3254 Fax: +82-32-460-3290

E-mail: leekwbm@gilhospital.com

Articles published in Obstet Gynecol Sci are open-access, distributed under the terms of the Creative Commons Attribution Non-Commercial License (http://creativecommons. org/licenses/by-nc/3.0/) which permits unrestricted non-commercial use, distribution, and reproduction in any medium, provided the original work is properly cited.

Copyright @ 2014 Korean Society of Obstetrics and Gynecology 


\section{Obstetrics \& Gynecology Science}

Chan-Yong Park, et al. Efficacy of GnRH agonist to prevent POF

fertilized oocytes [2]. The aim of this retrospective study was to evaluate the efficacy of gonadotropin-releasing hormone agonist $(\mathrm{GnRH}-\mathrm{a})$ in preventing development of ovarian failure in premenopausal gynecological cancer patients undergoing adjuvant chemotherapy.

\section{Materials and methods}

This retrospective study consisted of uterine cervical cancer and ovary cancer patients who were treated between March 2008 and June 2011 at Gachon University Gil Medical Center (GMC) in Incheon, Republic of Korea. The clinical and pathologic records were reviewed for all patients who underwent conservation of ovary or ovaries. The data were obtained using electronic patient records, and the following parameters were collected: histology, age, date of diagnosis, chemotherapy/addback therapy/GnRH-a regimen, number of cycles, follicle stimulating hormone (FSH) level, date of last follow-up. All treatment was given at the GMC, and electronic records of the GMC pharmacy were used to verify the chemotherapy/add-back therapy/GnRH-a regimen, dose, and number of cycles administered. Leuprolide acetate depot 3.75 mg (Ruprin, CJ, Seoul, Korea) was administered subcutaneously at least 1 week before the first cycle of chemotherapy and then every 4 week for the duration of chemotherapy. The last administration of Leuprolide acetate was given before the last cycle of chemotherapy.

Taxane and platinum based compounds are common agents in chemotherapy regimen of gynecologic cancer. There were three kinds of dose regimen used in this study population, as follows:

BEP: Belomycin $15 \mathrm{mg} / \mathrm{m}^{2}$, Etoposide $100 \mathrm{mg} / \mathrm{m}^{2}$, Cisplatin 20 $\mathrm{mg} / \mathrm{m}^{2}$

TP: Paclitaxel $175 \mathrm{mg} / \mathrm{m}^{2}$, Carboplatin target value AUC 5

CBDCA: Carboplatin target value AUC 5

FSH level was used as the biochemical marker of menopausal status and evaluated 4 weeks after the last cycle of chemotherapy. A FSH level above $40 \mathrm{IU} / \mathrm{L}$ indicated a post-menopausal status. Menstrual activity was recorded after chemotherapy in uterine preservation cases. The success of the experimental treatment was defined by the resumption of menstrual activity within 12 months after the last cycle of chemotherapy or by the occurrence of a FSH level $\leq 40 \mathrm{IU} / \mathrm{L}$ within 12 months after the last cycle of chemotherapy. During treatment a continuous estrogen or combined progestin preparation as add-back was administered every day. The add-back consisted of 1.03 mg 17b-estradiol and $0.5 \mathrm{mg}$ norethisterone acetate (Activelle, NovoNordisk, Seoul, Korea) in uterine conservation cases or estradiol (Progynova, Bayer, Seoul, Korea) in hysterectomy cases. Treatment with the GnRH-a plus add-back was continued until the chemotherapy was completed.

\section{Results}

In our institution, there were 221 women (134 cervical cancer, 87 ovarian cancer) who had undergone radical surgery. Of these, 14 premenopausal women (3 ovarian cancer, 11 cervical cancer) received a $\mathrm{GnRH}$-a for protection from chemotherapy induced ovarian failure and then they had the follow-up by single surgeon. The mean age was 31 years (range, 20-44 years), and the mean parity was $1.2 \pm 1.1$. One of the fourteen patients had both ovaries preserved, and the rest had unilateral ovary. Eleven cervical cancer patients who had undergone hysterectomy received estradiol (Progynova) for add-back therapy. Three ovarian cancer patients who received estradiol and norethisterone acetate (Activelle) resumed menstruation. During 116 days, the mean duration of chemotherapy, 4 to 6 cycles of depot injection of $\mathrm{GnRH}$-a were offered as the patients received 4 or 6 chemotherapy. Three protocols were used: BEP in ovarian cancer and CBDCA or CBDCA plus taxane in cervical cancer. The mean FSH level was $15.8 \mathrm{IU} / \mathrm{L}$. Only one of the 14 patients in the study group experienced premature ovarian failure (POF) with a FSH level $>40 \mathrm{IU} / \mathrm{L}$ and temporary vasomotor symptoms. After three months of estrogen therapy, FSH level was $6.49 \mathrm{IU} / \mathrm{L}$ and vasomotor symptoms were relieved. No patient developed POF within 1,306 days, the mean duration of follow-up. Although two patients became lost to follow-up, they had continued over 3 years of follow-up. One patient became pregnant following chemotherapy (Table 1).

\section{Discussion}

The strength of this study is that the study group maintained under clinical observation by single surgeon in single medical center, on leuprolide acetate activity in preventing chemotherapy-induced menopause. All patients exhibited a restoration of ovarian suppression after approximately 3.6 years of followup. Chemotherapy-related amenorrhea rates have been demonstrated to vary from $30 \%$ to $76 \%$ in several clinical studies, depending on the average age of the cohort and the 


\title{
Obstetrics \& Gynecology Science
}

\author{
Vol. 57, No. 6, 2014
}

Table 1. Patient's characteristics

\begin{tabular}{|lc|}
\hline Characteristics & Values \\
\hline Age (yr) & $31 \pm 6.5(20-44)$ \\
Parity & $1.2 \pm 1.1(0-3)$ \\
Diagnosis & \\
Ovarian cancer IC & $3 / 14(21.4)$ \\
Cervical cancer IB1 & $6 / 14(42.9)$ \\
Cervical cancer IB2 & $5 / 14(35.7)$ \\
Conservation of ovaries no. & \\
1 & $13 / 14(92.9)$ \\
2 & $1 / 14(7.1)$ \\
Hysterectomy & $11 / 14(78.6)$ \\
Chemotherapy cycle & \\
4 & $3 / 14(21.4)$ \\
6 & $11 / 14(78.6)$ \\
Duration (day) & $116 \pm 14.9$ \\
Regimen & \\
BEP & $3 / 14(21.4)$ \\
Taxane + CBDCA & $7 / 14(50.0)$ \\
CBDCA & $4 / 14(28.6)$ \\
Follicle stimulating hormone & $15.8 \pm 4.6$ \\
$\leq 40$ IU/L & $13 / 14(92.9)$ \\
$>40$ IU/L & $1 / 14(7.1)$ \\
Pregnancy & $1 / 14(7.1)$ \\
Gonadotropin-releasing hormone agonist cycle & \\
4 & $3 / 14(21.4)$ \\
6 & $11 / 14(78.6)$ \\
Add-back therapy & \\
Estrogen and progestin & $3 / 14(21.4)$ \\
Estrogen & $11 / 14(78.6)$ \\
Follow-up duration (day) & $1,306 \pm 369.1$ \\
\hline & $(859-1,884)$ \\
\hline
\end{tabular}

Values are presented as number (\%).

BEP, belomycin, etoposide, cisplatin; CBDCA, carboplatin.

used chemotherapeutic protocol [3-8]. Although taxane and platinum based compounds are common chemotherapeutic agents in gynecologic cancer, only cisplantin has been studied for its platinum-induced ovarian toxicity. In an in vitro human tissue model study, histological and immunohistochemical changes with primordial follicles destruction of ovarian injury induced by cisplatin was depicted. However, there is insufficient or only inconsistent evidence for the potential gonadotoxicity of taxane [9]. Fertility preservation before treatment is simple for male: banking of sperm. On the other hand, it is far more complicated in female since various factors such as age of patient, type of treatment, diagnosis, whether she has a partner, the time available and the high potential that gynecologic cancer has metastasized to her ovaries, must be taken in consideration [10].

Current options for preservation of fertility in gynecological cancer patients before the initiation of cancer-directed therapy are ovarian suppression or cryopreservation of embryos or unfertilized oocytes. The most effective and established means of preserving fertility in female cancer patient is embryo or oocyte cryopreservation. However, because of the requirements for scheduling and procedures, these interventions may entail a delay in cancer treatment. Besides, there is a necessity for a male partner or sperm donor to create an embryo, which can arouse ethical considerations. Alternatively, GnRH-a is a useful strategy for prevention of POF in case of extensive comorbidities associated with POF, compounded by poor compliance with or contraindications for hormonal therapy.

There are several possible mechanisms through which $\mathrm{GnRH}$-a may protect the ovary during chemotherapy. It is well known that prepubertal children receiving chemotherapy are more likely to maintain gonadal function than young adults. This allows for a hypothesis that inhibition of the hypothalamic-pituitary axis by GnRH-a may bring out quiescent gonads, simulating the prepubertal state, and thus rendering the gonads less susceptible to cytotoxic treatment $[11,12]$. Alternatively, the direct influence of $\mathrm{GnRH}$-a on the ovary and reduced blood flow to the ovary may suppress ovarian function, thus rendering the gonads less susceptible to cytotoxic treatment [13]. The effectiveness of a GnRH-a during chemotherapy to preserve ovarian function was first demonstrated in rodents and monkeys in the 1980s [14-16]. However, ovarian suppression through $\mathrm{GnRH}-\mathrm{a}$ or antagonist treatment during chemotherapy is highly controversial as a method to maintain fertility [17]. Blumenfeld et al. [18] first described the protective effect of GnRH-a on ovarian function when administered concomitantly with chemotherapy, and our study, as well as other previous studies, confirms these results [19-21]. In a cohort of 111 patients with lymphoma, 3.1\% and $37 \%$ of patients developed POF in the GnRH-a and retrospective control groups, respectively [22] (Table 2).

In contrast, Demeestere et al. [23] showed that there was no significant difference in chemotherapy induced POF after 1 year of follow-up between $\mathrm{GnRH}$-a treated patient versus control group in Hodgkin or non-Hodgkin lymphoma. A recent study demonstrated no benefit of using $\mathrm{GnRH}-\mathrm{a}$ in patients with breast cancer receiving cyclophosphamide-based chemotherapy 


\section{Obstetrics \& Gynecology Science}

Chan-Yong Park, et al. Efficacy of GnRH agonist to prevent POF

[24]. In this study, no differences were observed in menstruation resumption rates and hormonal and ultrasound markers of fertility 12 months after termination of chemotherapy between $\mathrm{GnRH}-\mathrm{a}$ treated patients versus the control group. Studies evaluating the efficacy of GnRH-a in humans have been limited by the lack of prospective data specifically addressing women of reproductive age who are at highest risk of infertility from chemotherapy, and GnRH-a are especially understudied in adolescents. Moreover, most human studies on GnRH-a have been small, uncontrolled, and/or retrospective [17]. It is hampered by several factors that estimation of risk of ovarian damage from chemotherapy for patients with different types of cancers. Historically ovarian function was assessed with nonobjective parameters such as menstrual history, which is not checkable in cases of hysterectomy, or vasomotor symptoms. Thus, more objective and reliable parameters are necessary, such as serum FSH levels, ovarian volume, antral follicle counts, and antimullerianhormone $(\mathrm{AMH})$ assessment [25-27]. Although FSH levels reflect function in the more mature follicle, $\mathrm{AMH}$ has been demonstrated to be a more reliable and reproducible indicator of ovarian reserve because it is an indicator of function in the primary and secondary follicle stages $[25,28]$.

In this study, FSH level was used as the biochemical marker of menopausal status and evaluated after the last cycle of chemotherapy. Menstrual activity was recorded after chemotherapy in uterine preservation cases. We need to consider additional assessments such as morphologic and ultrasound assessments for reduced follicle numbers and endocrine assessment for alterations in $\mathrm{FSH}, \mathrm{AMH}$, inhibin $\mathrm{B}$, and luteinizing hormone [29-31]. We had observed patients from the last chemotherapy cycle during 3.6 years. Lack of long-term follow-up of ovarian function in survivors often precludes the ability to distinguish between acute ovarian failure that resolves in the long term, permanent ovarian failure, and risk for development of premature menopause before the age of 40 years [32,33]. Because of the limited follow-up period, however, no prediction can be given on long-term fertility and subsequent development of POF in the future. Although the small size of study group, the heterogeneity of the treatment and absence of control group may be a limitation of this study, we have evaluated that the use of a GnRH-a during chemotherapy may have been effective for ovary protection in 14 premenopausal women with gynecologic cancer in shortterm. Twelve of the fourteen patients continue to be under our clinical observation. If we continue our clinical observation with these patients, further understanding of long-term effect of $\mathrm{GnRH}$-a to prevent premature menopause can be obtained. New patients are being enrolled for further study on chemotherapy-induced ovarian failure and retained consecutive observation. As the rate of young cancer survivors is increasing, fertility and ovarian function preservation for quality of life is becoming more relevant. Providing cancer patients with timely information related to the potential gonadotoxicity and options for fertility preservation is imperative.

\section{Conflict of interest}

No potential conflict of interest relevant to this article was reported.

Table 2. POF in other studies

\begin{tabular}{|c|c|c|c|c|c|}
\hline \multirow{2}{*}{ Author } & \multirow{2}{*}{ Disease } & \multicolumn{2}{|c|}{ Evaluated patient } & \multicolumn{2}{|c|}{ Amenorrhea/POF } \\
\hline & & Study & Control & Study & Control \\
\hline Blumenfeld et al. (1996) [18] & Lymphoma & 16 & 18 & $1(6)$ & $11(61)$ \\
\hline Castelo-Branco et al. (2007) [19] & Hodgkin's lymphoma & 30 & 26 & $27(90)$ & $6(23)$ \\
\hline Huser et al. (2008) [20] & Hodgkin's lymphoma & 72 & 45 & $15(21)$ & $32(71)$ \\
\hline Pereyra Pacheco et al. (2001) [21] & Leukemia & 12 & 4 & 0 & $4(100)$ \\
\hline Blumenfeld et al. (2008) [22] & Hodgkin's lymphoma & 65 & 46 & $2(3)$ & $17(37)$ \\
\hline Demeestere et al. (2013) [23] & Lymphoma & 25 & 24 & $5(20)$ & $5(19)$ \\
\hline Elgindy et al. (2013) [24] & Breast cancer & 50 & 50 & $10(20)$ & $10(20)$ \\
\hline Current study & Gynecologic cancer & 14 & NA & 0 & NA \\
\hline
\end{tabular}

Values are presented as number or number (\%).

POF, premature ovarian failure; NA, not applicable. 


\title{
Obstetrics \& Gynecology Science
}

\author{
Vol. 57, No. 6, 2014
}

\section{References}

1. National Cancer Information Center. Cancer incidence [Internet]. Goyang: National Cancer Information Center; 2012 [cited 2012 Oct 20]. Available from: http://www. cancer.go. $\mathrm{kr} / \mathrm{mbs} /$ cancer/index.jsp.

2. Levine J, Canada A, Stern CJ. Fertility preservation in adolescents and young adults with cancer. J Clin Oncol 2010;28:4831-41.

3. Abusief ME, Missmer SA, Ginsburg ES, Weeks JC, Partridge AH. The effects of paclitaxel, dose density, and trastuzumab on treatment-related amenorrhea in premenopausal women with breast cancer. Cancer 2010;116:791-8.

4. Burstein HJ, Winer EP. Primary care for survivors of breast cancer. N Engl J Med 2000;343:1086-94.

5. Goodwin PJ, Ennis M, Pritchard KI, Trudeau M, Hood N. Risk of menopause during the first year after breast cancer diagnosis. J Clin Oncol 1999;17:2365-70.

6. Hart R. Preservation of fertility in adults and children diagnosed with cancer. BMJ 2008;337:a2045.

7. Parulekar WR, Day AG, Ottaway JA, Shepherd LE, Trudeau ME, Bramwell $V$, et al. Incidence and prognostic impact of amenorrhea during adjuvant therapy in highrisk premenopausal breast cancer: analysis of a National Cancer Institute of Canada Clinical Trials Group Study: NCIC CTG MA.5. J Clin Oncol 2005;23:6002-8.

8. Stone FR, Slack RS, Novielli A, Ellis M, Baidas S, Gelmann $E$, et al. Rate of chemotherapy related amenorrhea associated with adjuvant Adriamycin and Cytoxan (AC) and Adriamycin and Cytoxan followed by Taxol (AC+ $\mathrm{T})$ in early stage breast cancer. Breast Cancer Res Treat 2000;64:224.

9. Ben-Aharon I, Shalgi R. What lies behind chemotherapyinduced ovarian toxicity? Reproduction 2012;144:153-63.

10. Roberts JE, Oktay K. Fertility preservation: a comprehensive approach to the young woman with cancer. J Natl Cancer Inst Monogr 2005;(34):57-9.

11. Pennisi AJ, Grushkin CM, Lieberman E. Gonadal function in children with nephrosis treated with cyclophosphamide. Am J Dis Child 1975;129:315-8.

12. Wallace WH, Shalet SM, Tetlow LJ, Morris-Jones PH. Ovarian function following the treatment of childhood acute lymphoblastic leukaemia. Med Pediatr Oncol 1993;21:333-9.
13. Blumenfeld $Z$. How to preserve fertility in young women exposed to chemotherapy? The role of GnRH agonist cotreatment in addition to cryopreservation of embrya, oocytes, or ovaries. Oncologist 2007;12:1044-54.

14. Ataya K, Ramahi-Ataya A. Reproductive performance of female rats treated with cyclophosphamide and/or LHRH agonist. Reprod Toxicol 1993;7:229-35.

15. Ataya K, Rao LV, Lawrence E, Kimmel R. Luteinizing hormone-releasing hormone agonist inhibits cyclophosphamide-induced ovarian follicular depletion in rhesus monkeys. Biol Reprod 1995;52:365-72.

16. Bokser L, Szende B, Schally AV. Protective effects of DTrp6-luteinising hormone-releasing hormone microcapsules against cyclophosphamide-induced gonadotoxicity in female rats. Br J Cancer 1990;61:861-5.

17. Blumenfeld Z, Eckman A. Preservation of fertility and ovarian function and minimization of chemotherapyinduced gonadotoxicity in young women by GnRH-a. J Natl Cancer Inst Monogr 2005;(34):40-3.

18. Blumenfeld Z, Avivi I, Linn S, Epelbaum R, Ben-Shahar M, Haim N. Prevention of irreversible chemotherapy-induced ovarian damage in young women with lymphoma by a gonadotrophin-releasing hormone agonist in parallel to chemotherapy. Hum Reprod 1996;11:1620-6.

19. Castelo-Branco C, Nomdedeu B, Camus A, Mercadal S, Martinez de Osaba MJ, Balasch J. Use of gonadotropinreleasing hormone agonists in patients with Hodgkin's disease for preservation of ovarian function and reduction of gonadotoxicity related to chemotherapy. Fertil Steril 2007;87:702-5.

20. Huser M, Crha I, Ventruba P, Hudecek R, Zakova J, Smardova $L$, et al. Prevention of ovarian function damage by a GnRH analogue during chemotherapy in Hodgkin lymphoma patients. Hum Reprod 2008;23:863-8.

21. Pereyra Pacheco B, Mendez Ribas JM, Milone G, Fernandez I, Kvicala R, Mila T, et al. Use of GnRH analogs for functional protection of the ovary and preservation of fertility during cancer treatment in adolescents: a preliminary report. Gynecol Oncol 2001;81:391-7.

22. Blumenfeld Z, Avivi I, Eckman A, Epelbaum R, Rowe $J M$, Dann EJ. Gonadotropin-releasing hormone agonist decreases chemotherapy-induced gonadotoxicity and premature ovarian failure in young female patients with Hodgkin lymphoma. Fertil Steril 2008;89:166-73.

23. Demeestere I, Brice P, Peccatori FA, Kentos A, Gaillard I, 


\section{Obstetrics \& Gynecology Science}

Chan-Yong Park, et al. Efficacy of GnRH agonist to prevent POF

Zachee P, et al. Gonadotropin-releasing hormone agonist for the prevention of chemotherapy-induced ovarian failure in patients with lymphoma: 1-year follow-up of a prospective randomized trial. J Clin Oncol 2013;31:903-9.

24. Elgindy EA, El-Haieg DO, Khorshid OM, Ismail El, Abdelgawad M, Sallam HN, et al. Gonadatrophin suppression to prevent chemotherapy-induced ovarian damage: a randomized controlled trial. Obstet Gynecol 2013;121:78-86.

25. Anderson RA, Themmen AP, Al-Qahtani A, Groome NP, Cameron DA. The effects of chemotherapy and longterm gonadotrophin suppression on the ovarian reserve in premenopausal women with breast cancer. Hum Reprod 2006;21:2583-92.

26. Scott RT, Opsahl MS, Leonardi MR, Neall GS, Illions EH, Navot D. Life table analysis of pregnancy rates in a general infertility population relative to ovarian reserve and patient age. Hum Reprod 1995;10:1706-10.

27. Lutchman Singh K, Davies M, Chatterjee R. Fertility in female cancer survivors: pathophysiology, preservation and the role of ovarian reserve testing. Hum Reprod Update 2005;11:69-89.

28. De Vet A, Laven JS, de Jong FH, Themmen AP, Fauser BC. Antimullerian hormone serum levels: a putative marker for ovarian aging. Fertil Steril 2002;77:357-62.

29. Bath $L E$, Wallace WH, Shaw MP, Fitzpatrick C, Anderson RA. Depletion of ovarian reserve in young women after treatment for cancer in childhood: detection by antiMüllerian hormone, inhibin B and ovarian ultrasound. Hum Reprod 2003;18:2368-74.

30. Bath LE, Anderson RA, Critchley HO, Kelnar CJ, Wallace WH. Hypothalamic-pituitary-ovarian dysfunction after prepubertal chemotherapy and cranial irradiation for acute leukaemia. Hum Reprod 2001;16:1838-44.

31. Van Beek RD, van den Heuvel-Eibrink MM, Laven JS, de Jong FH, Themmen AP, Hakvoort-Cammel FG, et al. Anti-Mullerian hormone is a sensitive serum marker for gonadal function in women treated for Hodgkin's lymphoma during childhood. J Clin Endocrinol Metab 2007;92:3869-74.

32. Sklar C. Reproductive physiology and treatment-related loss of sex hormone production. Med Pediatr Oncol 1999;33:2-8.

33. Sklar CA, Mertens AC, Mitby P, Whitton J, Stovall M, Kasper $C$, et al. Premature menopause in survivors of childhood cancer: a report from the childhood cancer survivor study. J Natl Cancer Inst 2006;98:890-6. 